Article

\title{
Identification, Cloning and Heterologous Expression of the Gene Cluster Directing RES-701-3, -4 Lasso Peptides Biosynthesis from a Marine Streptomyces Strain
}

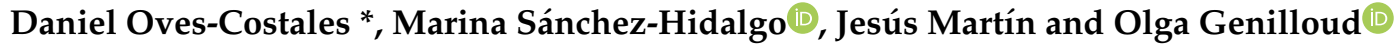 \\ Fundación MEDINA, Centro de Excelencia en Investigación de Medicamentos Innovadores en Andalucía, \\ Avda del Conocimiento 34, 18016 Armilla (Granada), Spain; marina.sanchez@medinaandalucia.es (M.S.-H.); \\ jesus.martin@medinaandalucia.es (J.M.); olga.genilloud@medinaandalucia.es (O.G.) \\ * Correspondence: daniel.oves@medinaandalucia.es; Tel.: + 34-958-993-965
}

Received: 17 March 2020; Accepted: 22 April 2020; Published: 1 May 2020

\begin{abstract}
RES-701-3 and RES-701-4 are two class II lasso peptides originally identified in the fermentation broth of Streptomyces sp. RE-896, which have been described as selective endothelin type $\mathrm{B}$ receptor antagonists. These two lasso peptides only differ in the identity of the C-terminal residue (tryptophan in RES-701-3, 7-hydroxy-tryptophan in RES-701-4), thus raising an intriguing question about the mechanism behind the modification of the tryptophan residue. In this study, we describe the identification of their biosynthetic gene cluster through the genome mining of the marine actinomycete Streptomyces caniferus CA-271066, its cloning and heterologous expression, and show that the seven open reading frames (ORFs) encoded within the gene cluster are sufficient for the biosynthesis of both lasso peptides. We propose that ResE, a protein lacking known putatively conserved domains, is likely to play a key role in the post-translational modification of the C-terminal tryptophan of RES-701-3 that affords RES-701-4. A BLASTP search with the ResE amino acid sequence shows the presence of homologues of this protein in the genomes of eight other Streptomyces strains, which also harbour the genes encoding the RES-701-3, -4 precursor peptide, split-B proteins and ATP-dependent lactam synthetase required for the biosynthesis of these compounds.
\end{abstract}

Keywords: lasso peptide; RES-701-3; RES-701-4; genome mining; biosynthetic gene cluster; Streptomyces caniferus

\section{Introduction}

Lasso peptides are a class of ribosomally synthesised and post-translationally modified peptides (RiPPs) natural products produced by the bacterial domain [1,2]. They have been shown to possess a wide range of biological properties, including antimicrobial activity against Gram-negative pathogens in the case of capistruin [3] and microcin J25 [4], antimicrobial activity against Gram-positive pathogens such as that exerted by siamycin-I [5] and the inhibition of HIV replication displayed in cell cultures by RP71955 [6]. A striking feature of lasso peptides, which sets them apart from other RiPPs, is their unusual topology. All of them display a macrolactam ring comprising seven to nine residues, formed between the $\mathrm{N}$-terminal $\alpha$-amino group and the $\beta$ - or $\gamma$-carboxyl group of aspartic or glutamic acid, with the remaining $C$-terminal peptide tail threaded through the ring. Additionally, the topology of some lasso peptides can be further modified by the presence of one or two disulfide bridges (class III and I lasso peptides respectively), although most of the known lasso peptides contain none (class II lasso peptides) [2]. The vast majority of lasso peptides have been isolated from terrestrial microorganisms; 
however, in recent years, some have been obtained from marine bacteria, including sungsanpin and aborycin $[7,8]$.

The advent of genomics in recent years has dramatically changed the landscape of lasso peptide discovery and research. Whereas, in the past, lasso peptides were serendipitously discovered employing untargeted bioactivity-guided approaches, now the field is flourishing with genome-mining based targeted strategies [9]. These strategies require the bioinformatic analysis of genomic information, and numerous platforms able to do so have been developed in recent years, such as antiSMASH (antibiotics and secondary metabolites analysis shell) [10], BAGEL (bacteriocin genome mining tool) [11], RiPPMiner (ribosomally synthesized post-translationally modified peptides miner) [12], PRISM (prediction informatics for secondary metabolomes) [13] and RODEO (rapid ORF description and evaluation online) [14]. The increasing number of lasso peptide biosynthetic gene clusters identified and characterised has also led to a better understanding of their biosynthesis. The minimum biosynthetic gene cluster comprises a gene encoding a precursor peptide (termed A), containing the leader and core peptides; a cysteine protease (termed B), which is involved in the maturation step and the assembly of the knot-like structure; and an ATP-dependent lactam synthetase (termed C), which is also required for the maturation step and the formation of the 7-9 residue macrolactam ring. Some lasso peptide gene clusters display a split B gene, with the B1 gene encoding for the $\mathrm{N}$-terminal region and the $\mathrm{B} 2$ gene for the $\mathrm{C}$-terminal part of a B protein encoded by an intact $\mathrm{B}$ gene [15]. Many lasso peptide gene clusters also contain a gene encoding for an $A B C$ transporter, which is presumably involved in the secretion of the lasso peptide. In other cases, a gene encoding for an isopeptidase is found in place of the $\mathrm{ABC}$ transporter. It has been proposed that clusters containing $\mathrm{ABC}$ transporters might encode lasso peptides with antimicrobial activity [2], whereas clusters containing isopeptidases might produce lasso peptides with other functions [16].

RES-701-3 and RES-701-4 (RES-701-3, -4) are two class II lasso peptides originally identified in the fermentation broth of Streptomyces sp. RE-896 while screening for endothelin antagonists [17-19]. Both compounds were shown to inhibit the endothelin 1 (ET-1) binding to the endothelin type B receptor $\left(\mathrm{ET}_{\mathrm{B}}\right)$, with $\mathrm{IC}_{50}$ values around $5-10 \mathrm{nM}$. Antagonists of ET-1 have been proposed as potential candidates for the treatment of diseases such as systemic hypertension, myocardial infarction, cardiac ischemia and diabetes mellitus, and numerous microbial natural products have been isolated during screening programs aiming to identify endothelin antagonists [20-23].

Chemical structures have been proposed for RES-701-3, -4 , and they only differ in the identity of the C-terminal residue, which is tryptophan in RES-701-3 and 7-hydroxy-tryptophan in RES-701-4 (Figure 1) [17]. Their structurally related congeners RES-701-1 and RES-701-2 share this structural feature, with RES-701-1 containing C-terminal tryptophan and RES-701-2 containing 7-hydroxy-tryptophan [18, 19]. It is reasonable to assume that the hydroxylation of position 7 of the C-terminal tryptophan in RES-701-1 and RES-701-3 leads to RES-701-2 and RES-701-4, respectively. Such hydroxylation is unlikely to happen during the isolation/purification of the compounds, and therefore is likely to occur enzymatically during the biosynthesis of the lasso peptides. In this study, we describe the identification, analysis, cloning and heterologous expression of the biosynthetic gene cluster directing RES-701-3 and -4 biosynthesis from the marine Streptomyces caniferus CA-271066.

\section{Results}

\subsection{Identification and in Silico Analysis of RES-701-3, -4 Biosynthetic Gene Cluster}

During our ongoing research with marine microorganisms, we identified Streptomyces caniferus CA-271066 as a producer of new bioactive metabolites [24]. The draft genome of this organism was analyzed with antiSMASH [10], which predicted 34 putative regions putatively encoding secondary metabolite gene clusters, including NRPS (non-ribosomal peptide synthetase), type I and II PKS (polyketide synthase), siderophores, terpenes and RiPPs. Careful examination of one of the RiPP gene 
clusters strongly suggested that it directed the biosynthesis of at least RES-701-3, based on the amino acid sequence predicted to be encoded by the precursor peptide gene res $A$ (Figure 2).

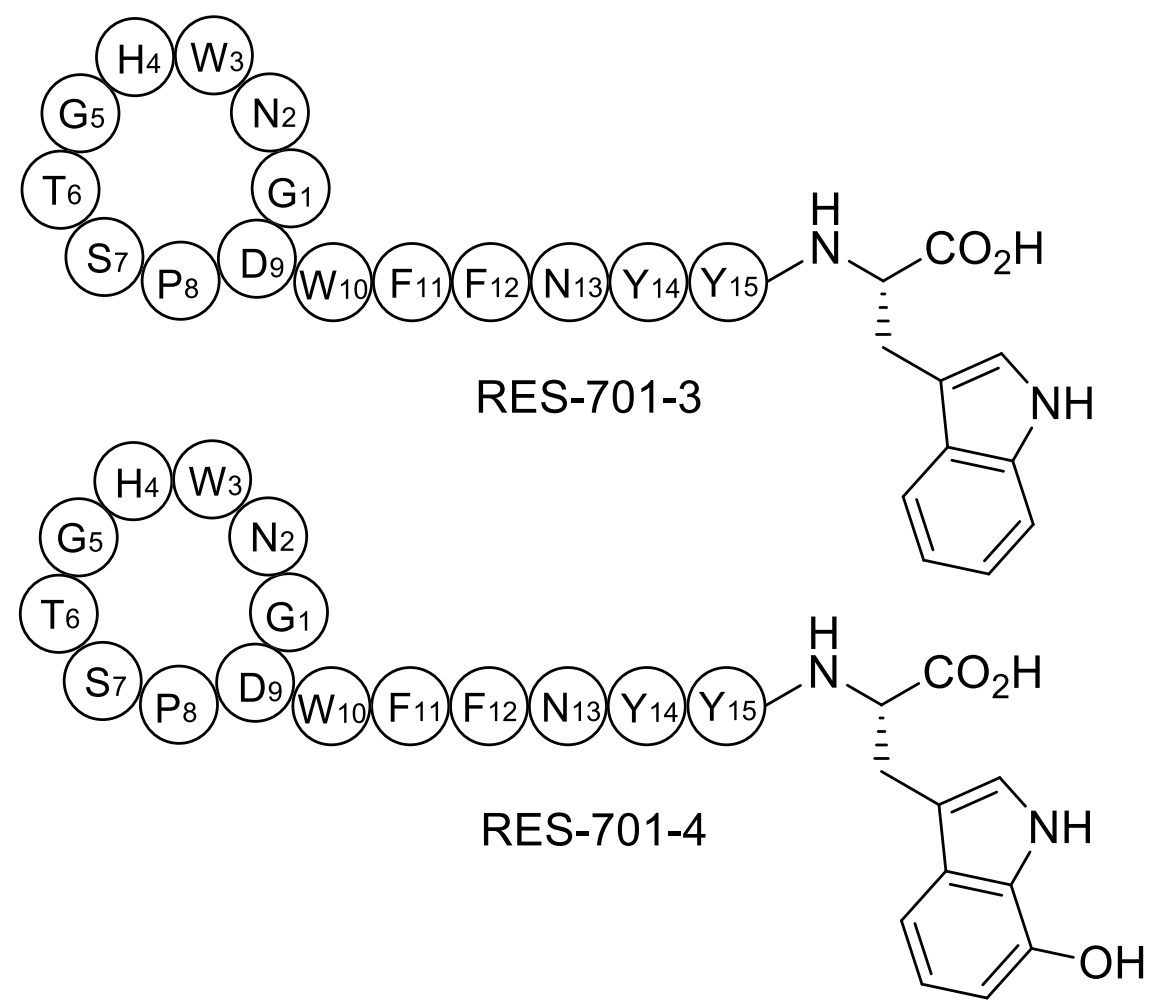

Figure 1. Structures of RES-701-3, -4 (pre-lasso conformation).

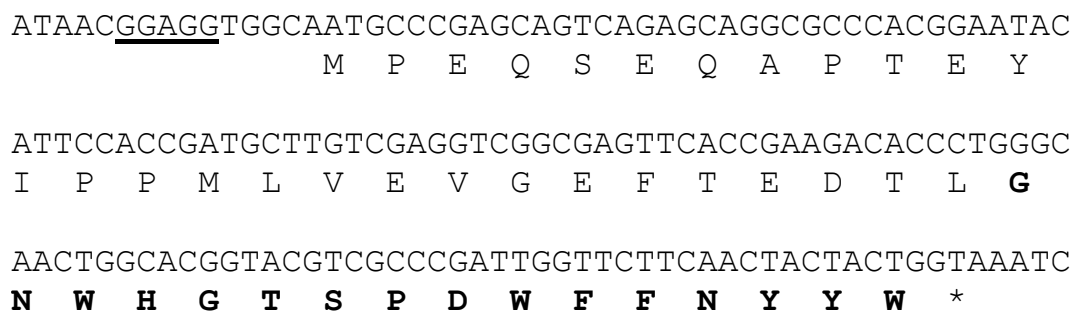

Figure 2. Nucleotide and deduced amino acid sequence of the $r e s A$ region. A putative ribosome-binding sequence is underlined and the structural peptide for RES-701-3, -4 is shown in bold characters.

A sequence analysis revealed the presence of seven ORFs located in a $7.7 \mathrm{~Kb}$ region (Figure 3). Interestingly, five of the ORFs (res $A, r e s C, r e s B 1, r e s B 2$ and resE) are unidirectionally transcribed, whereas the remaining two (resF and res $D$ ) are transcribed from the complementary strand. Additionally, res $B 1$ and resB2 are probably translationally coupled. res $A$ encodes a 44 aa (amino acid) precursor peptide, with the $\mathrm{C}$-terminal 16 aa region containing the core peptide and the remaining 28 aa from the $\mathrm{N}$-terminal region forming the leader peptide required for processing. A BLASTp homology search using the NCBI non-redundant protein sequence database was employed to analyze the proteins encoded by the remaining ORFs. resC encodes a 612 aa protein, which was found to be similar to SOE12204.1 (630 aa, 84\% identity, 89\% similarity) from Streptomyces sp. 2323.1. The protein contains a cd01991 domain, which is typically found in the asparagine synthase and ATP-dependent lactam synthetases. resB1 encodes an 84 aa protein similar to WP_106430390.1 (86 aa, 89\% identity, 90\% similarity) from Streptomyces auratus, and shows homology with the lasso peptide biosynthesis PqqD (pyrroloquinoline quinone biosynthesis) family chaperone. resB2 encodes a 145 aa protein similar to SOE12206.1 (145 aa, 88\% identity, 92\% similarity) from Streptomyces sp. 2323.1, containing the 
domain pfam13471. resE encodes a 209 aa hypothetical protein similar to WP_006604205.1 (209 aa, 86\% identity, 91\% similarity) from Streptomyces auratus, and lacks any known conserved domain. resF encodes a 551 aa protein similar to WP_119203701.1 (551 aa, 88\% identity, 94\% similarity) from Streptomyces sp. 2233, it contains a COG0531 domain and is proposed to be a member of the APC (Amino Acid-Polyamine-Organocation) family of transporters. Its three-dimensional structure is predicted to contain 14 transmembrane helices (TMHMM server v 2.0) [25]. resD encodes a 691 aa protein similar to WP_106430393.1 (648 aa, 78\% identity, 82\% similarity) from Streptomyces auratus with high homology to $\mathrm{ABC}$ transporters. It contains a COG1132 domain and its three-dimensional structure is predicted to contain six transmembrane helices [25].

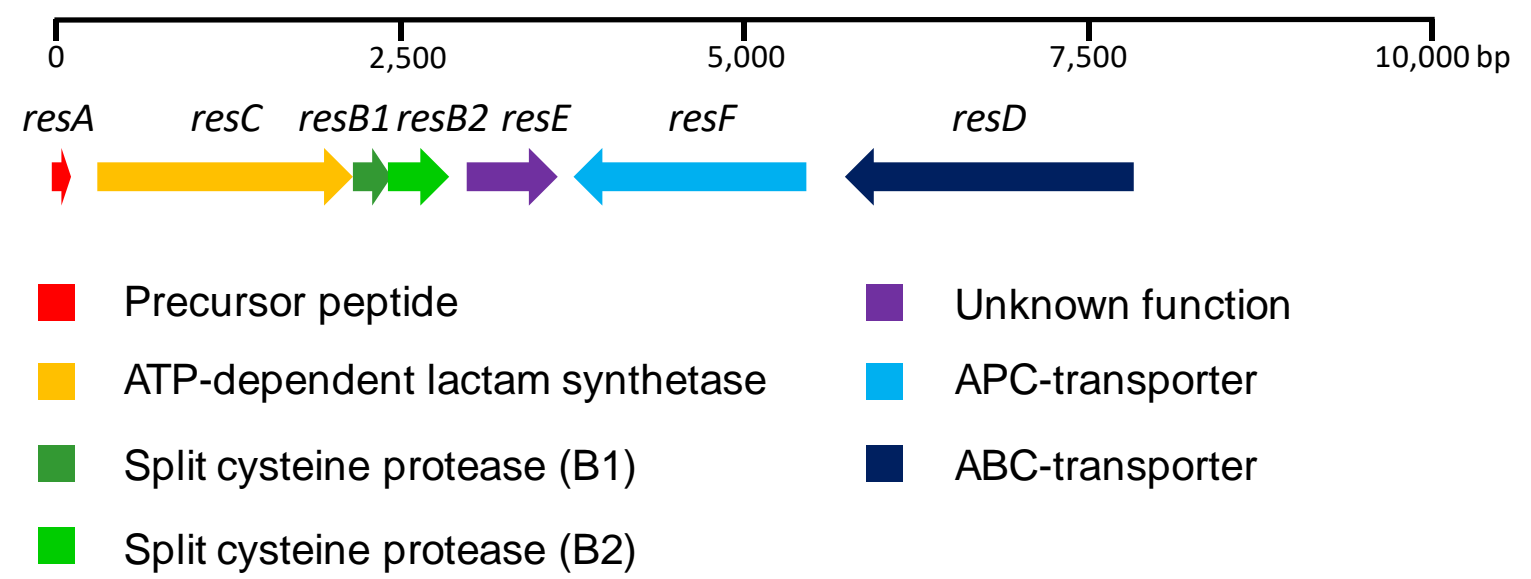

Figure 3. RES-701-3, -4 gene cluster from Streptomyces caniferus CA-271066.

The growth of Streptomyces caniferus CA-271066 did not lead to the production of RES-701-3, -4 under any of the fermentation conditions employed. Thus, we conceived a strategy based on heterologous expression in order to establish a link between the lasso peptides and their putative biosynthetic gene cluster.

\subsection{Cloning of resACB1B2EFD into the Vector $p C A P 01$}

A genomic region spanning $9.1 \mathrm{~Kb}$ and containing resACB1B2EFD was amplified by employing an overlapping-PCR approach. Over 700 nucleotides upstream of $r e s A$ and res $D$ were included in the amplified region in order to capture the putative promoter and the transcriptional and ribosome-binding sites. The $9.1 \mathrm{~Kb}$ SpeI/Xhol fragment was initially cloned into the $\mathrm{pCR}^{\mathrm{TM}}$-Blunt vector and transformed into NEB 10-beta E. coli. Clones were checked by restriction analysis, and a digested and purified SpeI/XhoI fragment was then cloned into the PCAP01 vector, a S. cerevisiae/E. coli/actinobacteria shuttle vector designed for the site-specific integration of the cloned gene cluster into the chromosomes of heterologous actinobacterial hosts, thanks to the $\phi C 31$ integration element present in the vector backbone, to generate pCAPRES [26]. Because pCAPRES contains a kanamycin-resistant marker, the direct transformation of the non-methylating CmR KmR E. coli strain ET12567/pUB307 is not possible. Thus, pCAPRES was used to transform the CmR E. coli strain ET12567, followed by triparental intergeneric conjugation employing E. coli ET12567/pCAPRES, ET12567/pUB307, and spores of the actinomycete host (Streptomyces coelicolor M1152, M1154, or Streptomyces albus J1074). Exconjugants were checked by PCR to confirm the integration of the putative biosynthetic gene cluster into the chromosomes of the heterologous hosts.

\subsection{Heterologous Expression of RES-701-3, -4 Gene Cluster and LC-ESI-TOF MS Analysis}

Positive exconjugants from Streptomyces coelicolor M1152, M1154 and Streptomyces albus J1074, together with negative controls (M1152, M1154 and J1074 conjugated with the empty vector pCAP01) were grown on five solid media (ISP2, ISP4, MYM, Minimal Medium and Supplemented Minimal 
Medium) for 6 days at $28^{\circ} \mathrm{C}$. The agar was then sliced and subjected to overnight n-butanol extraction. The solvent was removed, the residue resuspended in $20 \% \mathrm{DMSO} /$ water and analyzed by LC-HRESI-TOF (liquid chromatography-high resolution electrospray ionization-time of flight). The extracts from exconjugants M1152-pCAPRES and M1154-pCAPRES showed two new peaks at 3.68 and $3.81 \mathrm{~min}$ with $\mathrm{m} / \mathrm{z}$ values of 2096.8335 and 2080.8385 respectively, which were completely absent in the exconjugants M1152-pCAP01 and M1154-pCAP01 employed as negative controls (Figure 4). The component with mass 2096.8335 was assigned the molecular formula $\mathrm{C}_{103} \mathrm{H}_{115} \mathrm{~N}_{23} \mathrm{O}_{25} \mathrm{Na}^{+}$ (calculated mass 2096.8326, 0.43 ppm error), corresponding to the sodium adduct of RES-701-4, while the component with mass 2080.8385 was assigned the molecular formula $\mathrm{C}_{103} \mathrm{H}_{115} \mathrm{~N}_{23} \mathrm{O}_{24} \mathrm{Na}^{+}$ (calculated mass 2080.8377, 0.38 ppm error), corresponding to the sodium adduct of RES-701-3. The experimental isotopic patterns obtained for both components are in perfect agreement with the theorical ones calculated for such molecular formulae. The production of both components was maximised in supplemented minimal medium for M1154-pCAP01 and ISP-2 for M1152-pCAPRES, although the components could be detected in all the media employed in these two heterologous hosts. In general, a higher production of RES-701-4 compared to RES-701-3 was observed for all the growth conditions.
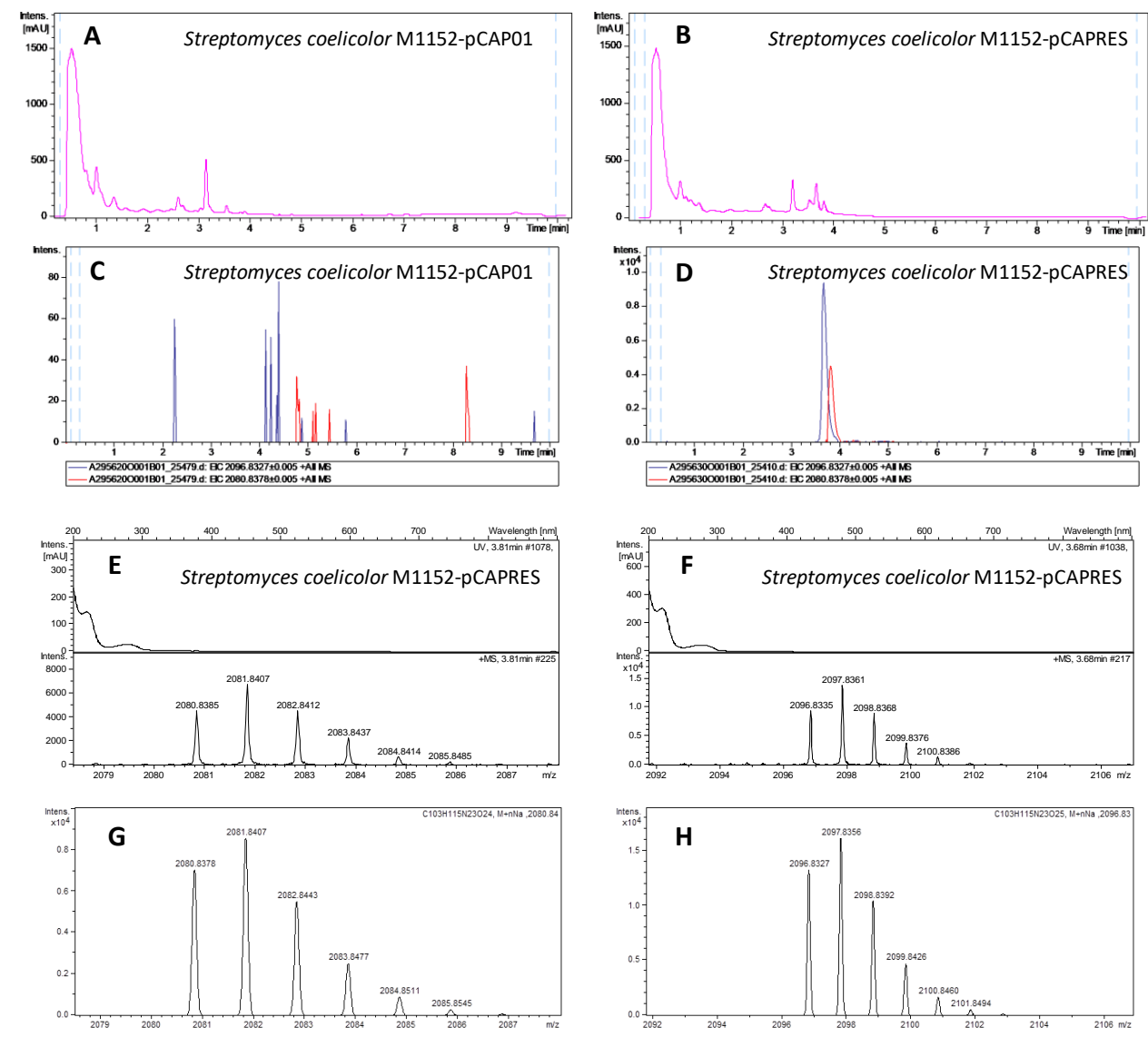

Figure 4. Heterologous expression of the RES-701-3, -4 gene cluster in Streptomyces coelicolor M1152. UV profiles at $210 \mathrm{~nm}$ of the negative control M1152-pCAP01 (A) and the positive exconjugant M1152-pCAPRES (B). Extracted Ion Chromatograms at $2080.8378 \pm 0.005$ (red trace, $\mathrm{C}_{103} \mathrm{H}_{115} \mathrm{~N}_{23} \mathrm{O}_{24} \mathrm{Na}^{+}$, RES-701-3) and $2096.8327 \pm 0.005$ (blue trace, $\mathrm{C}_{103} \mathrm{H}_{115} \mathrm{~N}_{23} \mathrm{O}_{25} \mathrm{Na}^{+}$, RES-701-4) in the extracts from the negative control M1152-pCAP01 (C, maximum intensity at around 80 counts) and the positive exconjugant M1152-pCAPRES (D, maximum intensity at around 10,000 counts). Zoomed-in image of the experimental MS isotopic patterns for the adducts $\mathrm{C}_{103} \mathrm{H}_{115} \mathrm{~N}_{23} \mathrm{O}_{24} \mathrm{Na}^{+}$(E) and $\mathrm{C}_{103} \mathrm{H}_{115} \mathrm{~N}_{23} \mathrm{O}_{25} \mathrm{Na}^{+}$(F) from the extract of the positive exconjugant M1152-pCAPRES. Theorical isotopic patterns for the adducts $\mathrm{C}_{103} \mathrm{H}_{115} \mathrm{~N}_{23} \mathrm{O}_{24} \mathrm{Na}^{+}(\mathbf{G})$ and $\mathrm{C}_{103} \mathrm{H}_{115} \mathrm{~N}_{23} \mathrm{O}_{25} \mathrm{Na}^{+}(\mathbf{H})$. 
On the other hand, no production of either RES-701-3 or RES-701-4 could be detected in any of the exconjugant J1074-pCAPRES clones employed under any of the growth conditions used.

\section{Discussion}

Post-translational modifications are unusual in lasso peptides, although a few examples have been reported recently, including the C-terminal phosphorylation in paeninodin [27], citrullination in citrulassin A [14], acetylation in albusnodin [28], C-terminal methylation of lassomycin and lassomycin-like lasso peptides $[29,30]$, and the epimerization of the $\alpha$-carbon from the C-terminal amino acid residue in MS-271 [31]. In this work, we prove that res $A C B 1 B 2 E F D$, identified through a genome-mining approach, is sufficient for the biosynthesis of the lasso peptide RES-701-3 and its 7-hydroxy-tryptophan homologue RES-701-4 employing Streptomyces coelicolor M1152 and M1154 as heterologous hosts. No production of either lasso peptide could be detected in any of the PCAPRES exconjugants from Streptomyces albus under any of the growth conditions, which shows the importance of employing different heterologous hosts, even if they are from the same genus. The heterologous expression of a lasso peptide in Streptomyces coelicolor and a lack of production in Streptomyces albus has also been observed in the case of albusnodin [28].

Based in their homologies and the identified conserved domains, plausible biosynthetic roles for proteins ResA, ResB1, ResB2 and ResC can be proposed. res $A$ encodes the precursor peptide. resB1 and resB2 encode for a "split" B protein; therefore, ResB1 is proposed to recognise and bind the leader peptide from ResA to deliver the structural peptide to ResB2 for processing [15]. resC encodes for a lactam synthetase, which is proposed to catalyze the ATP-dependent formation of the amide bond between the $\mathrm{N}$-terminal $\alpha$-amino group of Gly-1 and the $\beta$-carboxyl group of Asp-8 [32].

Many lasso peptide BGCs contain an ABC transporter, presumably involved in the secretion of the mature product, which is usually found downstream of the lactam synthetase-encoding gene. In the RES-701-3, -4 gene cluster resD encodes for an ABC-type transporter and is located in the complementary strand to resACB1B2E. resF is adjacent to resD and encodes for a 551 aa protein with 14 transmembrane helices that belongs to the Amino Acid-Polyamine-Organocation (APC) family of transporters. To the best of our knowledge, this is the first time that a member of this family of transporters has been found in a lasso peptide biosynthetic gene cluster, and is not clear what role, if any, it could play in RES-701-3, -4 biosynthesis. Presumably, the concerted action of ResD with additional $\mathrm{ABC}$ transporter components encoded elsewhere in the genome could be responsible for RES-701-3, -4 secretion.

On the other hand, resE is located downstream of resB2, and it encodes a medium-sized protein (209 aa), lacking any known conserved domain. Close homologues of ResE are found in the genomes of eight other Streptomyces strains. An analysis of the genomic context for these ResE analogues shows that all of them are encoded within homologous RES-701-3, -4 gene clusters (Figure 5), strongly suggesting that ResE is required for the biosynthesis of these lasso peptides.

A close inspection of the ResA protein shows that the C-terminal 16 aa region containing the structural peptide is identical in all the cases, and only minor differences are found in the $\mathrm{N}$-terminal region, corresponding to the leader peptide. In four of the cases, Streptomyces sp. 2314.4, Streptomyces sioyaensis, Streptomyces sp. 2333.5 and Streptomyces sp. 2112.2, the gene cluster organization is identical to that described here for Streptomyces caniferus CA-271066. Streptomyces auratus and Streptomyces angustmyceticus NRRL B-2347 contain the operon resACB1B2E and lack the genes resD and resF. Finally, in the case of Streptomyces sp. TM32 and Streptomyces sp. 2323.1 a number of ORFs encoding for proteins unrelated to lasso peptide biosynthesis are found embedded between res $F$ and res $D$. These data suggest that ResD and ResF might not be strictly required for RES-701-3, -4 biosynthesis. On the other hand, it is worth mentioning that in the case of Streptomyces angustmyceticus NRRL B-2347, resB2 and resE might be translationally coupled, which could suggest a coordinated action and/or protein-protein interaction between ResB2 and ResE [33]. More distantly related homologues of ResE can be found in the genomes of numerous other Streptomyces species, but there is a noticeable drop in 
the level of homology and an analysis of their genomic context shows that they are not encoded within lasso peptide gene clusters.

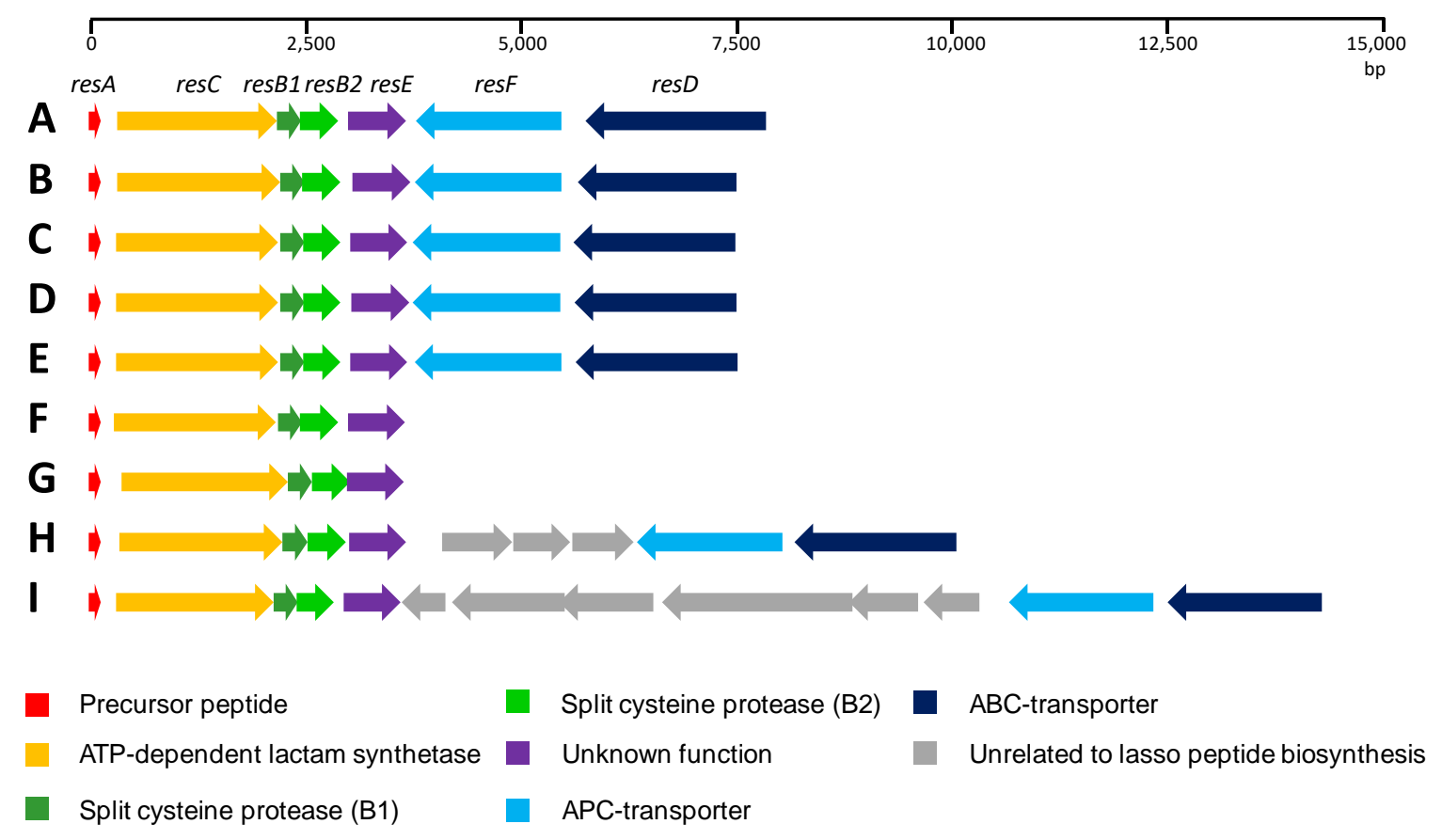

Figure 5. Comparison of the RES-701-3, -4 gene clusters found using a BLASTP homology search of ResE. Streptomyces caniferus CA-271066 (A); Streptomyces sp. 2314 (B); Streptomyces sioyaensis (C); Streptomyces sp. 2333.5 (D); Streptomyces sp. 2112.2 (E); Streptomyces auratus (F); Streptomyces angustmyceticus (G); Streptomyces TM32 (H); and Streptomyces sp. 2323.1 (I).

The fact that i) resACB1B2EFD is sufficient to produce both lasso peptides, ii) putative roles for ResA, ResC, ResB1 and ResB2 can be proposed based in their homologies, iii) ResD and ResF are transmembrane transporters and, as such, are unlikely to be involved in the conversion of RES-701-3 into RES-701-4 and iv) all of the closest homologues of ResE are encoded in homologous RES-701-3 or -4 gene clusters found in eight other Streptomyces species, lead us to hypothesise that ResE is likely to play a key role in the hydroxylation of position 7 of the C-terminal tryptophan of RES-701-3 or its pre-lasso intermediate in order to afford RES-701-4.

In summary, we report the identification, cloning and heterologous expression of the gene cluster encoding the biosynthesis of RES-701-3, -4. Our data unequivocally shows that res $A C B 1 B 2 E F D$ is sufficient for the production of both lasso peptides. Additionally, genome mining allowed us to identify eight other Streptomyces strains potentially containing the RES-701-3, -4 biosynthetic gene cluster, in which resE is universally conserved. We hypothesise that ResE is likely to play a key role in the hydroxylation required to generate RES-701-4, but further genetic and/or biochemical characterization work will be required to test this hypothesis and decipher the exact roles of ResE and ResF in the biosynthesis of these two lasso peptides.

\section{Materials and Methods}

\subsection{Bacterial Strains and Plasmids}

The strain Streptomyces caniferus CA-271066 was isolated from an ascidian collected at the seaside at 2 meters depth in São Tomé (São Tomé and Principe). A similarity-based search with the 16S rDNA sequence (1393 nt) against the EzBioCloud database indicated that the strain is closely related to Streptomyces caniferus DSM 41453(T) (100\% identity) [34]. NEB 10-beta competent E. coli (New England BioLabs, Ipswich, MA, USA), E. coli ET12567 (LGC Standards, Manchester, NH, USA) and E. coli 
ET12567/pUB307 (kindly provided by J.A. Salas) were employed throughout the cloning and conjugation processes, together with the vectors $\mathrm{PCR}^{\mathrm{TM}}$-Blunt (Thermo Fisher Scientific, Waltham, MA, USA) and pCAP01 (provided by Bradley Moore (Addgene plasmid \#59981; http://n2t.net/addgene:59981; RRID: Addgene_59981)) [26]. Streptomyces coelicolor M1152 and M1154 [35] were generously provided by M. Bibb. Streptomyces albus J1074 [36] was generously provided by J. A. Salas.

\subsection{Growth and Culture Conditions}

Streptomyces caniferus CA-271066 was typically cultured on ATCC-2 medium (soluble starch $20 \mathrm{~g} / \mathrm{L}$, glucose $10 \mathrm{~g} / \mathrm{L}$, NZ Amine Type E $5 \mathrm{~g} / \mathrm{L}$, meat extract $3 \mathrm{~g} / \mathrm{L}$, peptone $5 \mathrm{~g} / \mathrm{L}$, yeast extract $5 \mathrm{~g} / \mathrm{L}$, calcium carbonate $1 \mathrm{~g} / \mathrm{L}, \mathrm{pH} 7$ ) and grown on an orbital shaker at $28{ }^{\circ} \mathrm{C}, 220 \mathrm{rpm}$ and $70 \%$ relative humidity. E. coli strains were routinely cultured in LB Miller broth (Sigma-Aldrich, St. Louis, MO, USA) $\left(37^{\circ} \mathrm{C}\right.$, $250 \mathrm{rpm})$ and Difco LB Lennox agar $\left(37^{\circ} \mathrm{C}\right.$, static). Intergeneric conjugations were carried out on $\mathrm{MA}$ (MOPS $21 \mathrm{~g} / \mathrm{L}$, glucose $5 \mathrm{~g} / \mathrm{L}$, yeast extract $0.5 \mathrm{~g} / \mathrm{L}$, beef extract $0.5 \mathrm{~g} / \mathrm{L}$, casamino acids $1 \mathrm{~g} / \mathrm{L}$, agar $25 \mathrm{~g} / \mathrm{L}$, $\mathrm{pH}$ adjusted to 7). Exconjugants were grown on ISP2, ISP4, minimal medium, supplemented minimal medium [37] and MYM (maltose $4 \mathrm{~g} / \mathrm{L}$, yeast extract $4 \mathrm{~g} / \mathrm{L}$, malt extract $10 \mathrm{~g} / \mathrm{L}$, tap water $0.5 \mathrm{~L}$, milli-Q water $0.5 \mathrm{~L}$; once autoclaved add $2 \mathrm{~mL}$ of $\mathrm{R} 2$ trace elements stock). Antibiotics were supplemented when required for the selection of transformants at the following final concentrations: kanamycin $(50 \mu \mathrm{g} / \mathrm{mL})$, nalidixic acid $(25 \mu \mathrm{g} / \mathrm{mL})$, choramphenicol $(25 \mu \mathrm{g} / \mathrm{mL})$.

\subsection{General Molecular Biology Techniques}

Restriction endonucleases, Q5 High-Fidelity polymerase and the T4 DNA Ligase (Blunt/TA Ligase Master Mix) were purchased from New England Biolabs (Ipswich, MA, USA). Calf Intestinal Alkaline Phosphatase (CIAP) was purchased from Invitrogen (Waltham, MA, USA). All the primers employed were purchased at Sigma-Aldrich (St. Louis, MO, USA). A QIAprep Spin Miniprep Kit (Qiagen, Hilden, Germany) was employed for the purification of plasmid DNA from cells and the Illustra ${ }^{\mathrm{TM}}$ GFX $^{\mathrm{TM}}$ PCR DNA and Gel Band Purification Kit (GE Healthcare, Boston, MA, USA) was used for the purification of DNA amplicons from agarose gels and enzymatic reactions.

\subsection{PCR Amplifications of RES-701-3,-4 Biosynthetic Gene Cluster}

All attempts to amplify a 9.1 Kb DNA fragment containing the biosynthetic gene cluster failed. A strategy based on the amplification of two overlapping regions was thus employed. Region A was amplified using primers resAF 5'-TAAGCAACTAGTGGTGGAAGCCCCCTTTGG-3' (forward, SpeI restriction site underlined) and resAR 5'-GACTCAGGTCCCGCCCC-3' (reverse) on $50 \mu \mathrm{L}$ PCR mixtures containing $10 \mu \mathrm{L}$ Q5 buffer ( $5 \times), 0.2 \mathrm{mM}$ dNTPs, $0.5 \mu \mathrm{M}$ forward and reverse primers, $1 \mu \mathrm{L}$ of template DNA, $10 \mu \mathrm{L}$ of enhancer and $0.5 \mu \mathrm{L}$ of Q5 polymerase. The PCR conditions were $98^{\circ} \mathrm{C}$ for $30 \mathrm{~s}$, followed by 35 cycles at $98^{\circ} \mathrm{C}$ for $10 \mathrm{~s}, 70{ }^{\circ} \mathrm{C}$ for $30 \mathrm{~s}, 72^{\circ} \mathrm{C}$ for $3.5 \mathrm{~min}$, with a final elongation step at $72{ }^{\circ} \mathrm{C}$ during $5 \mathrm{~min}$. Region B was amplified using primers resBF $5^{\prime}$-CAGCGTTCGACAGCCTGG- $3^{\prime}$ (forward) and resBR 5'-TAAGCACTCGAGCAACGCTGTGTGAGGCCA-3' (reverse, XhoI restriction site underlined) on $50 \mu \mathrm{L}$ PCR mixtures containing $10 \mu \mathrm{L}$ Q5 buffer $(5 \times), 0.2 \mathrm{mM}$ dNTPs, $0.5 \mu \mathrm{M}$ forward and reverse primers, $1 \mu \mathrm{L}$ of template DNA, $10 \mu \mathrm{L}$ of enhancer and $0.5 \mu \mathrm{L}$ of Q5 polymerase. The PCR conditions were $98^{\circ} \mathrm{C}$ for $30 \mathrm{~s}$, followed by 35 cycles at $98^{\circ} \mathrm{C}$ for $10 \mathrm{~s}, 65^{\circ} \mathrm{C}$ for $30 \mathrm{~s}, 7{ }^{\circ} \mathrm{C}$ for $3.5 \mathrm{~min}$, with a final elongation step at $72{ }^{\circ} \mathrm{C}$ during $5 \mathrm{~min}$. Region A and region $\mathrm{B}$ amplicons were purified and employed in a two-step overlapping PCR with $50 \mu \mathrm{L}$ mixtures containing $10 \mu \mathrm{L}$ Q5 buffer, $0.4 \mathrm{mM}$ dNTPs, $10 \mu \mathrm{L}$ of enhancer, equimolecular amounts of the region $\mathrm{A}$ and $\mathrm{B}$ amplicons (ca. $500 \mathrm{ng}$ ), and $0.5 \mu \mathrm{L}$ of $\mathrm{Q} 5$ polymerase. The PCR conditions were $98^{\circ} \mathrm{C}$ for $30 \mathrm{~s}$, followed by 15 cycles at $98{ }^{\circ} \mathrm{C}$ for $10 \mathrm{~s}, 65^{\circ} \mathrm{C}$ for $30 \mathrm{~s}, 72{ }^{\circ} \mathrm{C}$ for $3.5 \mathrm{~min}$, with a final elongation step at $72{ }^{\circ} \mathrm{C}$ during $5 \mathrm{~min}$. Once finished, primers resAF and resBR were added at $0.5 \mu \mathrm{M}$ final concentration and the second PCR step was carried out: $98^{\circ} \mathrm{C}$ for $30 \mathrm{~s}$, followed by 30 cycles at $98^{\circ} \mathrm{C}$ for $10 \mathrm{~s}, 65^{\circ} \mathrm{C}$ for $30 \mathrm{~s}, 72{ }^{\circ} \mathrm{C}$ for $8 \mathrm{~min}$, with a final elongation step at $72{ }^{\circ} \mathrm{C}$ during $15 \mathrm{~min}$. The overlapped $9.1 \mathrm{~Kb}$ amplicon obtained was purified prior to its cloning. 


\subsection{Cloning of RES-701-3, -4 Biosynthetic Gene Cluster into the $p C P A 01$ Vector}

The 9.1 Kb amplicon containing RES-701-3, -4 gene cluster was initially cloned into the $\mathrm{pCR}^{\mathrm{TM}}$-Blunt vector using the Zero Blunt ${ }^{\mathrm{TM}}$ PCR Cloning kit (Thermo Fisher Scientific, Waltham, MA, USA). Briefly, ca. $975 \mathrm{ng}$ of the $9.1 \mathrm{~Kb}$ amplicon was mixed with $0.5 \mu \mathrm{L}$ of the $\mathrm{pCR}^{\mathrm{TM}}$-Blunt vector, $1.5 \mu \mathrm{L}$ of the ligase buffer, $1.5 \mu \mathrm{L}$ of the T4 DNA ligase and the mixture was incubated at room temperature during $90 \mathrm{~min}$. A total of $10 \mu \mathrm{L}$ of the mixture were then used to transform NEB 10-beta competent $E$. coli (New England BioLabs, Ipswich, MA, USA). The generated recombinant plasmids (pBLUNT-RES) were confirmed by a restriction analysis. pBLUNT-RES was digested with SpeI and XhoI and the resulting $9.1 \mathrm{~Kb}$ fragment was purified and ligated by $\mathrm{T} 4 \mathrm{DNA}$ ligase with the largest dephosphorylated SpeI/XhoI fragment of pCAP01, followed by the transformation of NEB 10-beta competent E. coli. The recombinant plasmids were analyzed by restriction digestion to obtain pCAPRES.

\subsection{Intergeneric Conjugation}

Plasmid pCAPRES was conjugated into Streptomyces hosts as previously described [26]. Briefly, purified pCAPRES was used to electroporate non-methylating E. coli ET12567. Cells from E. coli ET12567/pUB307 and E. coli ET12567/pCAPRES collected at an optical density of 0.4-0.6 were washed with LB twice to remove the antibiotics, resuspended and mixed with an adequate amount of freshly activated spores of S. coelicolor M1152, M1154 and S. albus J1074. The mixtures were plated on MA for triparental mating and overlaid after ca. $16 \mathrm{~h}$ with nalidixic acid $(25 \mu \mathrm{g} / \mathrm{mL})$ and kanamycin $(50 \mu \mathrm{g} / \mathrm{mL})$. After a few days of incubation, some of the exconjugants were streaked on MA plates containing nalidixic acid $(25 \mu \mathrm{g} / \mathrm{mL})$ and kanamycin $(50 \mu \mathrm{g} / \mathrm{mL})$ and five colonies from each Streptomyces heterologous host were picked and streaked on ISP-2 plates. The insertion of pCAPRES into the Streptomyces hosts chromosomes was checked by PCR employing the genomic DNA of the exconjugants and the primers resBF and resBR.

\subsection{Heterologous Expression of RES-701-3,-4 Gene Cluster and LC-ESI-TOF Analysis}

Seed cultures on ATCC-2 of the recombinant strains S. coelicolor M1152, M1154 and S. albus J1074 harbouring RES-701-3, -4 BGC, together with the corresponding negative controls, were used to inoculate Petri plates with ISP2, ISP4, MYM, minimal medium and supplemented minimal medium. The plates were incubated at $28^{\circ} \mathrm{C}$ for 6 days and then the agar was sliced and subjected to extraction with $\mathrm{n}-\mathrm{BuOH}$. The organic solvent was evaporated to dryness and the extract was resuspended to a final ratio of $20 \% \mathrm{DMSO} /$ water. The microbial extracts were filtered and analyzed employing a Bruker maXis QTOF mass spectrometer coupled to a HPLC system, as previously described [38].

Author Contributions: D.O.-C. carried out the bioinformatic analysis, cloning and heterologous expression. J.M. carried out the LC-HRMS analysis and interpreted the ESI-TOF spectra. D.O.-C., M.S.-H. and O.G. conceived and designed the research. D.O.-C wrote the original draft of the paper, which was revised, edited and approved by all the authors. All authors have read and agreed to the published version of the manuscript.

Funding: This research received no external funding.

Acknowledgments: The authors acknowledge M. Estévez, B. Martos and F. Muñoz for their technical support. We thank Juan Pablo Gómez Escribano, Mervyn Bibb and the John Innes Centre for generously providing strains Streptomyces coelicolor M1152 and Streptomyces coelicolor M1154. We also thank José Antonio Salas and the University of Oviedo for kindly providing strains Streptomyces albus J1074 and Escherichia coli ET12567/pUB307, and Bradley Moore for kindly providing plasmid pCAP01 (Addgene plasmid \#59981; http://n2t.net/addgene:59981; RRID: Addgene_59981).

Conflicts of Interest: The authors declare no conflict of interest. 


\section{References}

1. Arnison, P.G.; Bibb, M.J.; Bierbaum, G.; Bowers, A.A.; Bugni, T.S.; Bulaj, G.; Camarero, J.A.; Campopiano, D.J.; Challis, G.L.; Clardy, J.; et al. Ribosomally synthesized and post-translationally modified peptide natural products: Overview and recommendations for a universal nomenclature. Nat. Prod. Rep. 2013, 30, 108-160. [CrossRef] [PubMed]

2. Hegemann, J.D.; Zimmermann, M.; Xie, X.; Giessen, T.W. Lasso Peptides: An Intriguing Class of Bacterial Natural Products. Acc. Chem. Res. 2015, 48, 1909-1919. [CrossRef] [PubMed]

3. Kuznedelov, K.; Semenova, E.; Knappe, T.A.; Mukhamedyarov, D.; Srivastava, A.; Chatterjee, S.; Ebright, R.H.; Marahiel, M.A.; Severinov, K. The Antibacterial Threaded-lasso Peptide Capistruin Inhibits Bacterial RNA Polymerase. J. Mol. Boil. 2011, 412, 842-848. [CrossRef] [PubMed]

4. Delgado, M.A.; Rintoul, M.R.; Farías, R.N.; Salomón, R.A. Escherichia coli RNA Polymerase Is the Target of the Cyclopeptide Antibiotic Microcin J25. J. Bacteriol. 2001, 183, 4543-4550. [CrossRef] [PubMed]

5. Tan, S.; Ludwig, K.C.; Müller, A.; Schneider, T.; Nodwell, J.R. The Lasso Peptide Siamycin-I Targets Lipid II at the Gram-Positive Cell Surface. ACS Chem. Boil. 2019, 14, 966-974. [CrossRef] [PubMed]

6. Frechet, D.; Guitton, J.D.; Herman, F.; Faucher, D.; Helynck, G.; Du Sorbier, B.M.; Ridoux, J.P.; James-Surcouf, E.; Vuilhorgne, M. Solution structure of RP 71955, a new 21 amino acid tricyclic peptide active against HIV-1 virus. Biochemistry 1994, 33, 42-50. [CrossRef]

7. Um, S.; Kim, Y.-J.; Kwon, H.N.; Wen, H.; Kim, S.-H.; Kwon, H.C.; Park, S.; Shin, J.; Oh, D.-C. Sungsanpin, a Lasso Peptide from a Deep-Sea Streptomycete. J. Nat. Prod. 2013, 76, 873-879. [CrossRef]

8. Shao, M.; Ma, J.; Li, Q.; Ju, J. Identification of the Anti-Infective Aborycin Biosynthetic Gene Cluster from Deep-Sea-Derived Streptomyces sp. SCSIO ZS0098 Enables Production in a Heterologous Host. Mar. Drugs 2019, 17, 127. [CrossRef]

9. Cheung-Lee, W.L.; Link, A.J. Genome mining for lasso peptides: Past, present, and future. J. Ind. Microbiol. Biotechnol. 2019, 46, 1371-1379. [CrossRef]

10. Blin, K.; Shaw, S.; Steinke, K.; Villebro, R.; Ziemert, N.; Lee, S.Y.; Medema, M.H.; Weber, T. antiSMASH 5.0: Updates to the secondary metabolite genome mining pipeline. Nucleic Acids Res. 2019, 47, W81-W87. [CrossRef]

11. Van Heel, A.J.; De Jong, A.; Song, C.; Viel, J.H.; Kok, J.; Kuipers, O.P. BAGEL4: A user-friendly web server to thoroughly mine RiPPs and bacteriocins. Nucleic Acids Res. 2018, 46, W278-W281. [CrossRef] [PubMed]

12. Agrawal, P.; Khater, S.; Gupta, M.; Sain, N.; Mohanty, D. RiPPMiner: A bioinformatics resource for deciphering chemical structures of RiPPs based on prediction of cleavage and cross-links. Nucleic Acids Res. 2017, 45, W80-W88. [CrossRef] [PubMed]

13. Skinnider, M.A.; Merwin, N.J.; Johnston, C.W.; Magarvey, N.A. PRISM 3: Expanded prediction of natural product chemical structures from microbial genomes. Nucleic Acids Res. 2017, 45, W49-W54. [CrossRef]

14. Tietz, J.; Schwalen, C.J.; Patel, P.S.; Maxson, T.; Blair, P.M.; Tai, H.-C.; Zakai, U.I.; Mitchell, D.A. A new genome-mining tool redefines the lasso peptide biosynthetic landscape. Nat. Methods 2017, 13, 470-478. [CrossRef] [PubMed]

15. Zhu, S.; Fage, C.; Hegemann, J.D.; Mielcarek, A.; Yan, D.; Linne, U.; Giessen, T.W. The B1 Protein Guides the Biosynthesis of a Lasso Peptide. Sci. Rep. 2016, 6, 35604. [CrossRef] [PubMed]

16. Maksimov, M.O.; Link, A.J. Discovery and Characterization of an Isopeptidase That Linearizes Lasso Peptides. J. Am. Chem. Soc. 2013, 135, 12038-12047. [CrossRef]

17. Ogawa, T.; Ochiai, K.; Tanaka, T.; Tsukuda, E.; Chiba, S.; Yano, K.; Yamasaki, M.; Yoshida, M.; Matsuda, Y. RES-701-2, -3 and -4, Novel and Selective Endothelin Type B Receptor Antagonists Produced by Streptomyces sp. I. Taxonomy of Producing Strains, Fermentation, Isolation, and Biochemical Properties. J. Antibiot. 1995, 48, 1213-1220. [CrossRef]

18. Yano, K.; Yamasaki, M.; Yoshida, M.; Matsuda, Y.; Yamaguchi, K. RES-701-2, a Novel and Selective Endothelin Type B Receptor Antagonist Produced by Streptomyces sp. II. Determination of the Primary Structure. J. Antibiot. 1995, 48, 1368-1370. [CrossRef] 
19. Yamasaki, M.; Yano, K.; Yoshida, M.; Matsuda, Y.; Yamaguchi, K. RES-701-1, a novel and selective endothelin type B receptor antagonist produced by Streptomyces sp. RE-701. II. Determination of the primary sequence. J. Antibiot. 1994, 47, 276-280. [CrossRef]

20. Kojiri, K.; Ihara, M.; Nakajima, S.; Kawamura, K.; Funaishi, K.; Yano, M.; Suda, H. Endothelin-binding inhibitors, BE-18257A and Be-18257B. I. Taxonomy, fermentation, isolation and characterization. J. Antibiot. 1991, 44, 1342-1347. [CrossRef]

21. Miyata, S.; Ohhata, N.; Murai, H.; Masui, Y.; Ezaki, M.; Takase, S.; Nishikawa, M.; Kiyoto, S.; Okuhara, M.; Kohsaka, M. WS009 A and B, new endothelin receptor antagonists isolated from Streptomyces sp. No. 89009. I. Taxonomy, fermentation, isolation, physico-chemical properties and biological activities. J. Antibiot. 1992, 45, 1029-1040. [CrossRef] [PubMed]

22. Miyata, S.; Fukami, N.; Neva, M.; Takase, S.; Kiyoto, S. WS-7338, new endothelin receptor antagonists isolated from Streptomyces sp. No. 7338. III. Structures of WS-7338 A, B, C and D and total synthesis of WS-7338 B. J. Antibiot. 1992, 45, 788-791. [CrossRef] [PubMed]

23. Lam, Y.K.T.; Williams, D.L.; Sigmund, J.M.; Sanchez, M.; Genilloud, O.; Kong, Y.L.; Stevens-Miles, S.; Huang, L.; Garrity, G.M. Cochinmicins, novel and potent cyclodepsipeptide endothelin antagonists from a Microbispora sp. I. Production, isolation, and characterization. J. Antibiot. 1992, 45, 1709-1716. [CrossRef] [PubMed]

24. Pérez-Victoria, I.; Oves-Costales, D.; Lacret, R.; Martín, J.; Sanchez-Hidalgo, M.; Díaz-Navarro, C.; Cautain, B.; Vicente, F.; Genilloud, O.; Reyes, F. Structure elucidation and biosynthetic gene cluster analysis of caniferolides A-D, new bioactive 36-membered macrolides from the marine-derived Streptomyces caniferus CA-271066. Org. Biomol. Chem. 2019, 17, 2954-2971. [CrossRef] [PubMed]

25. Krogh, A.; Larsson, B.; Von Heijne, G.; Sonnhammer, E. Predicting transmembrane protein topology with a hidden markov model: Application to complete genomes11Edited by F. Cohen. J. Mol. Boil. 2001, 305, 567-580. [CrossRef] [PubMed]

26. Yamanaka, K.; Reynolds, K.A.; Kersten, R.D.; Ryan, K.S.; González, D.J.; Nizet, V.; Dorrestein, P.C.; Moore, B.S. Direct cloning and refactoring of a silent lipopeptide biosynthetic gene cluster yields the antibiotic taromycin A. Proc. Natl. Acad. Sci. USA 2014, 111, 1957-1962. [CrossRef]

27. Zhu, S.; Hegemann, J.D.; Fage, C.; Zimmermann, M.; Xie, X.; Linne, U.; Giessen, T.W. Insights into the Unique Phosphorylation of the Lasso Peptide Paeninodin*. J. Boil. Chem. 2016, 291, 13662-13678. [CrossRef]

28. Zong, C.; Cheung-Lee, W.L.; Elashal, H.E.; Raj, M.; Link, A.J. Albusnodin: An acetylated lasso peptide from Streptomyces albus. Chem. Commun. 2018, 54, 1339-1342. [CrossRef]

29. Gavrish, E.; Sit, C.S.; Cao, S.; Kandror, O.; Spoering, A.; Peoples, A.; Ling, L.; Fetterman, A.; Hughes, D.; Bissell, A.; et al. Lassomycin, a ribosomally synthesized cyclic peptide, kills mycobacterium tuberculosis by targeting the ATP-dependent protease ClpC1P1P2. Chem. Boil. 2014, 21, 509-518. [CrossRef]

30. Su, Y.; Han, M.; Meng, X.; Feng, Y.; Luo, S.; Yu, C.; Zheng, G.; Zhu, S. Discovery and characterization of a novel C-terminal peptide carboxyl methyltransferase in a lassomycin-like lasso peptide biosynthetic pathway. Appl. Microbiol. Biotechnol. 2019, 103, 2649-2664. [CrossRef]

31. Feng, Z.; Ogasawara, Y.; Nomura, S.; Dairi, T. Biosynthetic Gene Cluster of a d-Tryptophan-Containing Lasso Peptide, MS-271. ChemBioChem 2018, 19, 2045-2048. [CrossRef] [PubMed]

32. Duquesne, S.; Destoumieux-Garzón, D.; Zirah, S.; Goulard, C.; Péduzzi, J.; Rebuffat, S. Two Enzymes Catalyze the Maturation of a Lasso Peptide in Escherichia coli. Chem. Boil. 2007, 14, 793-803. [CrossRef] [PubMed]

33. Oppenheim, D.S.; Yanofsky, C. Translational Coupling during Expression of the Tryptophan Operon of Escherichia Coli. Genetics 1980, 95, 785-795.

34. Yoon, S.-H.; Ha, S.-M.; Kwon, S.; Lim, J.; Kim, Y.; Seo, H.; Chun, J. Introducing EzBioCloud: A taxonomically united database of $16 \mathrm{~S}$ rRNA gene sequences and whole-genome assemblies. Int. J. Syst. Evol. Microbiol. 2017, 67, 1613-1617. [CrossRef] [PubMed]

35. Gomez-Escribano, J.P.; Bibb, M.J. Engineering Streptomyces coelicolor for heterologous expression of secondary metabolite gene clusters. Microb. Biotechnol. 2011, 4, 207-215. [CrossRef]

36. Chater, K.F.; Wilde, L.C. Streptomyces albus G Mutants Defective in the SalGI Restriction-Modification System. Microbiol. 1980, 116, 323-334. [CrossRef] 
37. Kieser, T.; Bibb, M.J.; Buttner, M.J.; Chater, K.F.; Hopwood, D.A. Practical Streptomyces Genetics, 2nd ed.; The John Innes Foundation: Norwich, UK, 2000; pp. 405-420.

38. Martín, J.; Crespo, G.; González-Menéndez, V.; Moreno, G.P.; Sánchez-Carrasco, P.; Pérez-Victoria, I.; Ruiz-Perez, L.-M.; González-Pacanowska, D.; Vicente, F.; Genilloud, O.; et al. MDN-0104, an Antiplasmodial Betaine Lipid from Heterospora chenopodii. J. Nat. Prod. 2014, 77, 2118-2123. [CrossRef]

(C) 2020 by the authors. Licensee MDPI, Basel, Switzerland. This article is an open access article distributed under the terms and conditions of the Creative Commons Attribution (CC BY) license (http://creativecommons.org/licenses/by/4.0/). 